\title{
Comparative Analysis of All-Sky Luminous Efficacy Models Based on Calculated and Measured Solar Radiation Data of Four Worldwide Cities
}

\author{
Donghyun Seo \\ Chungbuk National University, Cheongju, Republic of Korea \\ Correspondence should be addressed to Donghyun Seo; seodh@cbnu.ac.kr
}

Received 26 January 2018; Accepted 18 April 2018; Published 11 July 2018

Academic Editor: K. R. Justin Thomas

Copyright (c) 2018 Donghyun Seo. This is an open access article distributed under the Creative Commons Attribution License, which permits unrestricted use, distribution, and reproduction in any medium, provided the original work is properly cited.

\begin{abstract}
Luminous efficacy model uses solar radiation data to generate illuminance data, and its performance also depends on the quality of solar radiation data. Various luminous efficacy models are reviewed and evaluated to select a universal luminous efficacy model. Since most luminous efficacy models are fitted with specific local climate characteristics, the model that has the least locality as well as accuracy is a mandatory requirement. Three representative luminous efficacy models are selected and evaluated with measured solar radiation and illuminance data from four worldwide cities. It was found that all the evaluated models provide good predictions (over $0.96 R^{2}$ value) for both global and diffuse illuminance. Among them, the Perez luminous efficacy model shows the highest performance in terms of accuracy and bias. However, illuminance data prediction based on estimated solar radiation data is more common practice rather than those from measured solar data. The performance of the selected luminous efficacy models is evaluated when recently proposed universal solar radiation model supplies predicted solar radiation data. The result indicates that the quality of estimated solar radiation data has a much deeper impact on the performance of the luminous efficacy model. Within the current limited technology and measured data resource, the consecutive processing of the modified Zhang and Huang solar model and Perez luminous efficacy model could provide the best option to predict both global and diffuse solar radiation and illuminance. But, users of the model-based illuminance data should interpret their simulation results with the error (30\% 40\% in RMSE and $\pm 6 \%$ in $\mathrm{MBE})$ in predicting global and diffuse illuminance.
\end{abstract}

\section{Introduction}

Luminous efficacy in daylight is defined as the ratio of illuminance to solar radiation that is expressed in $\mathrm{Lm} / \mathrm{W}$. Luminous efficacy model is one of the essential parts in detailed building energy simulation tools to evaluate the performance of daylighting systems and their controls because measured illuminance data are scarce and are even more difficult to obtain than measured solar radiation data in most cities in the world. The vast majorities of building energy and daylighting simulation tools rely on modeled illuminance data rather than measured data. For example, EnergyPlus adopts the Perez luminous efficacy model [1] and DOE-2 [2] uses the average value model to artificially generate outdoor illuminance data when the data is missing in input weather file. However, there are currently no comprehensive detailed building energy simulation tools that have a credible luminous efficacy model for worldwide cities because most of the models use site-dependent correlation coefficients. The development of universal models for predicting solar radiation and illuminance levels is an important part of the development of a comprehensive building energy simulation tool.

In this study, several luminous efficacy models are investigated to assess their performance and applicability as a universal all-sky luminous efficacy model. First, a detailed review of all-sky luminous efficacy models is presented. Then, a comparative analysis of the performance of a few selected 
models is implemented using measured data that are acquired from worldwide cities including in Europe, America, and Asia. Finally, a universal luminous efficacy model is proposed for predicting outdoor luminance levels and evaluated its performance when this model is combined with the universal solar model [3].

\section{Problem Definition}

When hourly solar radiation data are available, instantaneous daylight illuminance data can be estimated using luminous efficacy models. The clear-sky global and beam luminous efficacy models mainly depend on solar radiation and solar altitude angle [4-6]. The attenuation effect of atmospheric conditions is modeled using factors such as clearness index, optical air mass, sky brightness, and sky clearness [1, 6-9]. Pons et al. [10] performed a sensitivity analysis using atmospheric parameters and found that the luminous efficacy varied considerably depending on the physical parameter considered by the model. Specifically, they found that the variations between model predictions are significant when water vapor and aerosol content vary. Therefore, any site-specific coefficients may not be applicable to other climatic regions. It is not feasible to develop site-specific coefficients of universal luminous efficacy model that works well in any cities since measured data are very limited. It may be desirable to evaluate existing models that could be used as a universal model with recognized error in the context of the recognized problem. In the following sections, all-sky luminous efficacy models are reviewed to see if they have the potential as a universal model.

\section{Literature Review}

3.1. All-Sky Luminous Efficacy Models. Muneer and Kinghorn [7] have used clearness index, $K_{\mathrm{T}}$, for the calculation of global $\left(K_{\mathrm{g}}\right)$ and diffuse $\left(K_{\mathrm{d}}\right)$ luminous efficacy.

$$
\begin{aligned}
& K_{\mathrm{g}}=136.6-74.541 K_{\mathrm{T}}+57.3421 K_{\mathrm{T}}^{2}(\mathrm{~lm} / \mathrm{W}), \\
& K_{\mathrm{d}}=130.2-39.828 K_{\mathrm{T}}+49.9797 K_{\mathrm{T}}^{2}(\mathrm{~lm} / \mathrm{W}) .
\end{aligned}
$$

Igawa et al. [11] proposed an all-sky luminous efficacy model with zenith angle $\left(\theta_{z}\right)$ and measured global radiation from Kyoto for 1993 1994. This model was simplified by Umemiya et al. [12] by introducing $K_{\mathrm{T}}$ and showed better performance. Ruiz and Rebledo [9] developed various luminous efficacy models based on the Muneer and Kinghorn model by changing local coefficients and some independent variables. The performance of the modified Muneer and Kinghorn models is similar for both global and diffuse luminous efficacy models. Particularly, the model used a diffuse fraction, $K_{\mathrm{D}}$, instead of $K_{\mathrm{T}}$. It showed slightly better accuracy than the Muneer and Kinghorn model.

Littlefair [6] suggested an all-sky luminous efficacy model using measured sky diffuse and ground-reflected diffuse with cloud cover in the UK. Beam, sky diffuse, and groundreflected fractions of the global illuminance (or irradiance) are also used for global luminous efficacy.

$$
\begin{aligned}
& K_{\mathrm{d}}=144-29 \bullet C C / 8, \\
& K_{\mathrm{b}}=51.8+1.646 \mathrm{~h}-0.01513 \mathrm{~h}^{2}, \\
& K_{\mathrm{g}}=R_{\mathrm{B}} K_{\mathrm{b}}+R_{\mathrm{D}} K_{\mathrm{d}}+R_{\mathrm{G}} K_{\mathrm{gr}},
\end{aligned}
$$

where CC is the cloud cover expressed in oktas. This value can be obtained using sunshine probability $\sigma(\mathrm{CC} / 8=$ $\left.1-0.55 \sigma+1.22 \sigma^{2}-1.68 \sigma^{3}\right)$. The sunshine probability can be replaced with the equation, $K_{\mathrm{d}}=\left(1-R_{\mathrm{D}}\right) K_{\mathrm{cl}}+R_{\mathrm{D}} K_{\mathrm{oc}}$, by Muneer and Angus [13, 14].

$K_{\mathrm{b}}$ is the beam luminous efficacy. $K_{\mathrm{d}}$ is the diffuse luminous efficacy. $K_{\mathrm{gr}}$ is the ground-reflected diffuse luminous efficacy of $86(\mathrm{~lm} / \mathrm{W}) . R_{\mathrm{B}}, R_{\mathrm{D}}$, and $R_{\mathrm{G}}$ are the beam, sky diffuse, and ground-reflected fraction of the global illuminance (or irradiance), respectively.

Perez et al. [1] have proposed more comprehensive luminous efficacy models involving several independent variables. Specifically, they found the global luminous efficacy varies with sky clearness, sky brightness $(\Delta)$, zenith angle, and cloud amount. Sky clearness is a function of diffuse and direct normal irradiance that characterizes the optical transparency of the cloud cover, sky brightness is a function of optical air mass and diffuse irradiance that represents the transition from overcast through partly cloudy to clear skies, and atmospheric precipitable water content (W) expressed by dew-point temperature is utilized to describe all-sky conditions. They also have tried to verify the applicability of their model's locally developed coefficients $\left(a_{\mathrm{i}}\right.$, $\left.b_{\mathrm{i}}, c_{\mathrm{i}}, d_{\mathrm{i}}\right)$ to other locations. However, they considered sites located only in the Northern US and Western Europe in the verification.

$$
K_{\mathrm{b}}=\max \left\{0, a_{\mathrm{i}}+b_{\mathrm{i}} \mathrm{W}+c_{\mathrm{i}} \exp (5.73 \theta z-5)+d_{\mathrm{i}} \Delta\right\}(\operatorname{lm} / \mathrm{W}),
$$

$K_{\mathrm{d}}=\left(a_{\mathrm{i}}+b_{\mathrm{i}} \mathrm{W}+c_{\mathrm{i}} \cos \theta_{z}+d_{\mathrm{i}} \ln \Delta\right)(\operatorname{lm} / \mathrm{W})$.

Du Mortier et al. [15] developed all-sky beam, diffuse, and global models for ESRA (CEC of European Solar Radiation Atlas) and CIBSE (Chartered Institute of Building Services Engineer) Guide J. They introduced the nebulosity index (NI) to calculate a pseudo cloud cover. They used optical air mass, Rayleigh scattering coefficient, and solar altitude angle to estimate the nebulosity index.

The main input variables for the Olseth and Skartveit model [8] include solar altitude angle, $h$ [deg], ordinal number of the day, $J$, and the $K_{\mathrm{T}}$. Olseth and Skartveit divided sky conditions into clear, overcast, and bright cloud to estimate diffuse luminous efficacy. Thus, three efficacy components $K_{\mathrm{d}, \mathrm{cl}}, K_{\mathrm{d}, \mathrm{oc}}$, and $K_{\mathrm{d} \text {,br }}$ are separately calculated and summed up to estimate the total diffuse luminous efficacy.

Derived from simultaneously recorded illuminance and solar irradiance data, average value models have been proposed by several researchers. This type of models is both simple and powerful because excluding low solar altitude angles, high-variable turbidities, and high densities of aerosol, the values are usually constant throughout the common variation range for the $K_{\mathrm{T}}$. Blackwell [16] concluded that global efficacy varied between 105 and $128 \mathrm{~lm} / \mathrm{W}$ for average 
TABle 1: Performance summary of various luminous efficacy models in various location.

(a)

\begin{tabular}{|c|c|c|c|c|}
\hline Models & Type & MBE (lx) & RMSE (lx) & Reference: city used in the research \\
\hline Constant $(110 \mathrm{~lm} / \mathrm{W})$ & Global & -1667.0 & 3277.0 & [18]: Edinburgh, UK \\
\hline Constant $(120 \mathrm{~lm} / \mathrm{W})$ & Diffuse & -82.0 & 1870.0 & [18]: Edinburgh, UK \\
\hline \multirow{4}{*}{ Littlefair [6] } & Global & -767.0 & 2842.0 & [18]: Edinburgh, UK \\
\hline & Diffuse & -945.0 & 1580.0 & [18]: Edinburgh, UK \\
\hline & Global & -1120.0 & 2210.0 & [18]: London, UK \\
\hline & Diffuse & 100.0 & 990.0 & [18]: London, UK \\
\hline \multirow{2}{*}{ Perez [1] } & Global & 410.0 & 1160.0 & [18]: London, UK \\
\hline & Diffuse & 180.0 & 660.0 & [18]: London, UK \\
\hline
\end{tabular}

(b)

\begin{tabular}{|c|c|c|c|c|}
\hline Models & Yield & MBE (\%) & RMSE (\%) & Reference: city used in the research \\
\hline Constant $(110 \mathrm{~lm} / \mathrm{W})$ & Global & 0.6 & 8.2 & [17]: Arcavacata, Italy \\
\hline Constant $(120 \mathrm{~lm} / \mathrm{W})$ & Diffuse & 3.7 & 20.2 & [17]: Arcavacata, Italy \\
\hline Constant $(110 \mathrm{~lm} / \mathrm{W})$ & Global & -2.1 & 6.7 & [17]: Osaka, Japan \\
\hline Constant $(120 \mathrm{~lm} / \mathrm{W})$ & Diffuse & 8.7 & 15.0 & [17]: Osaka, Japan \\
\hline Littlefair [6] & Global & -1.6 & 10.4 & [19]: Helsinki, Finland \\
\hline \multirow{6}{*}{ Perez [1] } & Global & -0.6 & 6.7 & [19]: Helsinki, Finland \\
\hline & Global & -4.1 & 10.2 & [17]: Arcavacata, Italy \\
\hline & Diffuse & 8.2 & 24.4 & [17]: Arcavacata, Italy \\
\hline & Global & -6.5 & 10.1 & [17]: Osaka, Japan \\
\hline & Diffuse & 5.9 & 16.4 & [17]: Osaka, Japan \\
\hline & Global & 12.0 & 13.0 & Muneer, 2005: Fukuoka, Japan \\
\hline \multirow[t]{3}{*}{ Olseth and Skartveit [8] } & Global & -0.4 & 8.0 & [19]: Helsinki, Finland \\
\hline & Global & 4.3 & 9.4 & [19]: Helsinki, Finland \\
\hline & Global & 3.3 & 9.4 & [17]: Arcavacata, Italy \\
\hline \multirow[t]{3}{*}{ Muneer and Kinghorn [7] } & Diffuse & 3.7 & 19.9 & [17]: Arcavacata, Italy \\
\hline & Global & 2.2 & 5.3 & [17]: Osaka, Japan \\
\hline & Diffuse & 6.4 & 14.3 & [17]: Osaka, Japan \\
\hline
\end{tabular}

sky conditions. Muneer and Angus [14] has suggested allsky, average global, and diffuse luminous efficacy values of 110 and $120 \mathrm{~lm} / \mathrm{W}$, respectively. It has been reported in the literature that the average values are dependent on geographic and atmospheric characteristics. Some of these average value models are used in detailed building energy simulation programs such as DOE-2 [2].

\section{Comparative Analysis for a Universal Luminous Efficacy Model Selection}

4.1. Criteria on Measured and Calculated Data Agreement. $\mathrm{MBE}$ (mean bias error) and RMSE (root mean square error) are used in the researches as a measure of the degree of agreement between measured $\left(x_{\text {true, } \mathrm{i}}\right)$ and calculated $\left(x_{\text {calc, } \mathrm{i}}\right)$ illuminance data. Since those two values usually written as a percentage error by multiplying by $100 \%, \mathrm{MBE}(\%)$ and RMSE (\%) are also used.

$$
\begin{aligned}
\mathrm{MBE} & =\frac{1}{n} \sum_{i=1}^{n} \frac{x_{\text {calc, } \mathrm{i}}-x_{\text {true }, \mathrm{i}}}{x_{\text {true }, \mathrm{i}}}, \\
\mathrm{RMSE} & =\sqrt{\frac{1}{n} \sum_{i=1}^{n}\left(\frac{x_{\text {calc } \mathrm{i}}-x_{\text {true } \mathrm{i}}}{x_{\text {true }, \mathrm{i}}}\right)^{2}},
\end{aligned}
$$

where $n$ is the number of data.

4.2. Candidate Model Selection. Validation analyses of all-sky luminous efficacy models against available measured illuminance data have been carried out by several researchers [17-19]. While a few researchers tried to develop locally fitted coefficients, most of the analyses used original coefficients since measured data are not available. Table 1 provides performance summary of various luminous efficacy models that are implemented with various local weather data and fitted for original coefficients.

Muneer et al. [18] compared the Littlefair model [6] with the average value model and Perez model [1] to estimate the 
TABLE 2: Measured irradiance and illuminance data of selected cities.

\begin{tabular}{lccccccc}
\hline Station, country & Latitude & Longitude & Elev $(\mathrm{m})$ & Time zone & Source & Illum. data & Year \\
\hline Lyon, France & $45^{\circ} 47^{\prime} \mathrm{N}$ & $4^{\circ} 55^{\prime} \mathrm{E}$ & 170 & GMT+1 & IDMP & Global/diffuse & $1994(8760$ points) \\
Golden, CO, USA & $39^{\circ} 74^{\prime} \mathrm{N}$ & $105^{\circ} 18^{\prime} \mathrm{W}$ & 1829 & GMT-7 & NREL & Global & $2006-07(17520$ points) \\
Fukuoka, Japan & $33^{\circ} 35^{\prime} \mathrm{N}$ & $130^{\circ} 27^{\prime} \mathrm{E}$ & 12 & GMT+9 & IDMP & Global/diffuse & $1994(552$ points) \\
Manchester, UK & $53^{\circ} 28^{\prime} \mathrm{N}$ & $2^{\circ} 14^{\prime} \mathrm{W}$ & 38 & GMT+0 & IDMP & Global/diffuse & 1993 (864 points) \\
\hline
\end{tabular}

model performance in Edinburgh and London, UK. They found that the Littlefair model shows good performance in predicting global and diffuse luminous efficacy since the Littlefair model has developed with southern UK cities which are very close to the two cities. In spite of this fact, the Perez model yields more accurate predictions with lower MBE and RMSE statistics.

Vartiainen [19] compared Littlefair [6], Perez [1], Olseth and Skartveit [8], and Muneer and Kinghorn [7] models with measured illuminance and irradiance at Helsinki, Finland. He found that the Perez model provides the lowest RMSE values similar to the Olseth and Skartveit model (1998) which is developed with the measured data at Bergen, Norway. On the other hand, he found that the Littlefair model slightly underestimates while the Muneer and Kinghorn model overestimates the luminous efficacy levels with some wider dispersion than the Littlefair and Perez models.

Cucumo et al. [17] compared prediction performance of the Muneer and Kinghorn, Perez, Ruiz, and Muneer and Robeldo models with developed simplified global and diffuse luminance efficacy models. In the comparison with 5 different cities, the Perez global luminous efficacy model shows relatively high MBE and RMSE in Arcavacata, Italy, and Osaka, Japan.

In summary, several studies have indicated that the luminous efficacy models provide generally accurate predictions. Most of the models, however, are based on site-specific coefficients; they may be applicable to other sites with caution. Several reported comparative analyses have indicated that the Perez model [1] provides generally better predictions than other models. In detail, Perez et al. [1] reported global illuminance prediction RMSE of 3\% and MBE of less than $1 \%$ for six American and European sites. For diffuse illuminance, RMSE values of 2-6\% (overcast), 5-9\% (intermediate), and 10-15\% (clear) have been observed. However, Cucumo et al. [17] reported that the Perez model did not outperform other considered luminous efficacy models in southern Europe and Japan. It is also worthwhile to mention that the diffuse luminous efficacy models are generally low prediction performance than that of the global model.

Further comparative analysis using measured data from geographically broader sites should be performed to confirm the prediction accuracy of various luminous efficacy models including the Perez model. The following section summarizes the results of a comparative analysis carried out in this study in order to establish a universal luminous efficacy model.

\section{Performance Evaluation of the Selected Models with Measured Data from Europe, USA, and Japan}

5.1. Measured Data Preparation. In this section, introduction of measured data gathered from four worldwide cities is provided to investigate the consistent performance of selected luminous efficacy models: average value, Littlefair, and Perez models. Table 2 summarizes the general information of measured data used in this comparative analysis. Measured data for Lyon (Vaulx-en-Velin), France, is acquired from the International Daylight Measurement Program database [20]. This data has been subjected to the IDMP quality control procedure. Data for Fukuoka, Japan, and Manchester, UK, are acquired from Muneer et al. [21]; but originally, they are recorded by IDMP. The data from Golden, CO, USA, is obtained from NREL Solar Radiation Research Lab [22]. It is worthwhile to note that global horizontal irradiance (GHI) for Golden, CO, USA, is measured with various sensors with different wavelength ranges. Therefore, a value of GHI is slightly different for each sensor and the other sites. However, this site is included in this research to test the consistent performance of the selected models with respect to the geographical difference.

5.2. Comparative Analysis Results. Three luminous efficacy models have been selected to carry out the comparative analysis against the measured data described in Table 2. The selected models include the Perez model [1], average value model $(110 \mathrm{~lm} / \mathrm{W}$ for global illuminance and $120 \mathrm{~lm} / \mathrm{W}$ for diffuse illuminance), and Littlefair model [6]. Table 3 summarizes the MBE (\%), RMSE (\%), and $R^{2}$ results for all the models against measured illuminance data at each site.

In general, the Perez model provides good performance among the models in global illuminance prediction especially in Lyon, France, although the $R^{2}$ values are not noticeably different in all the cities. Among the tested cities, error of all three models goes worse in Manchester, UK, and Fukuoka, Japan. They are geographically distanced from the cities that are used in the original model development. In case of the average value model, in spite of its simplicity, it shows a comparable performance to those of the Perez and Littlefair models. Littlefair model yields the worst performance among the considered models; but still, this model provides high $R^{2}$ values in the range of 0.96 0.99 for both global and diffuse illuminance.

Like other previous researches, this luminous efficacy model performance analysis results with four geographically separated cities show that localities of models are found but 
TABLE 3: Summary of the comparative analysis for selected luminous efficacy models.

\begin{tabular}{|c|c|c|c|c|c|c|c|}
\hline \multirow{2}{*}{ Station, country (measured year) } & \multirow{2}{*}{ Model } & \multicolumn{3}{|c|}{ Global illuminance } & \multicolumn{3}{|c|}{ Diffuse illuminance } \\
\hline & & $\operatorname{MBE}(\%)$ & RMSE (\%) & $R^{2}$ & $\operatorname{MBE}(\%)$ & RMSE (\%) & $R^{2}$ \\
\hline \multirow{3}{*}{ Lyon, France (1994) } & Perez & -0.4 & 7.3 & 0.99 & -4.3 & 12.5 & 0.97 \\
\hline & Average & 0.2 & 8.1 & 0.99 & -2.2 & 12.2 & 0.94 \\
\hline & Littlefair & -3.2 & 13.1 & 0.99 & 0.0 & 10.9 & 0.96 \\
\hline \multirow{3}{*}{ Golden, CO. USA (2007) } & Perez & 0.2 & 10.4 & 0.99 & - & - & - \\
\hline & Average & 2.4 & 8.4 & 0.99 & - & - & - \\
\hline & Littlefair & -6.1 & 19.3 & 0.97 & - & - & - \\
\hline \multirow{3}{*}{ Manchester, UK (1993) } & Perez & -9.3 & 11.4 & 0.99 & -13.5 & 16.7 & 0.99 \\
\hline & Average & -11.0 & 13.9 & 0.99 & -7.9 & 11.5 & 0.99 \\
\hline & Littlefair & -4.4 & 15.3 & 0.97 & 4.4 & 9.8 & 0.99 \\
\hline \multirow{3}{*}{ Fukuoka, Japan (1994) } & Perez & -8.1 & 12.0 & 0.98 & -21.0 & 24.1 & 0.98 \\
\hline & Average & -8.6 & 11.5 & 0.98 & -18.6 & 21.5 & 0.97 \\
\hline & Littlefair & -8.7 & 15.5 & 0.96 & -7.4 & 10.6 & 0.98 \\
\hline
\end{tabular}

TABle 4: Comparative analysis of global luminous efficacy models' performance for four worldwide cities.

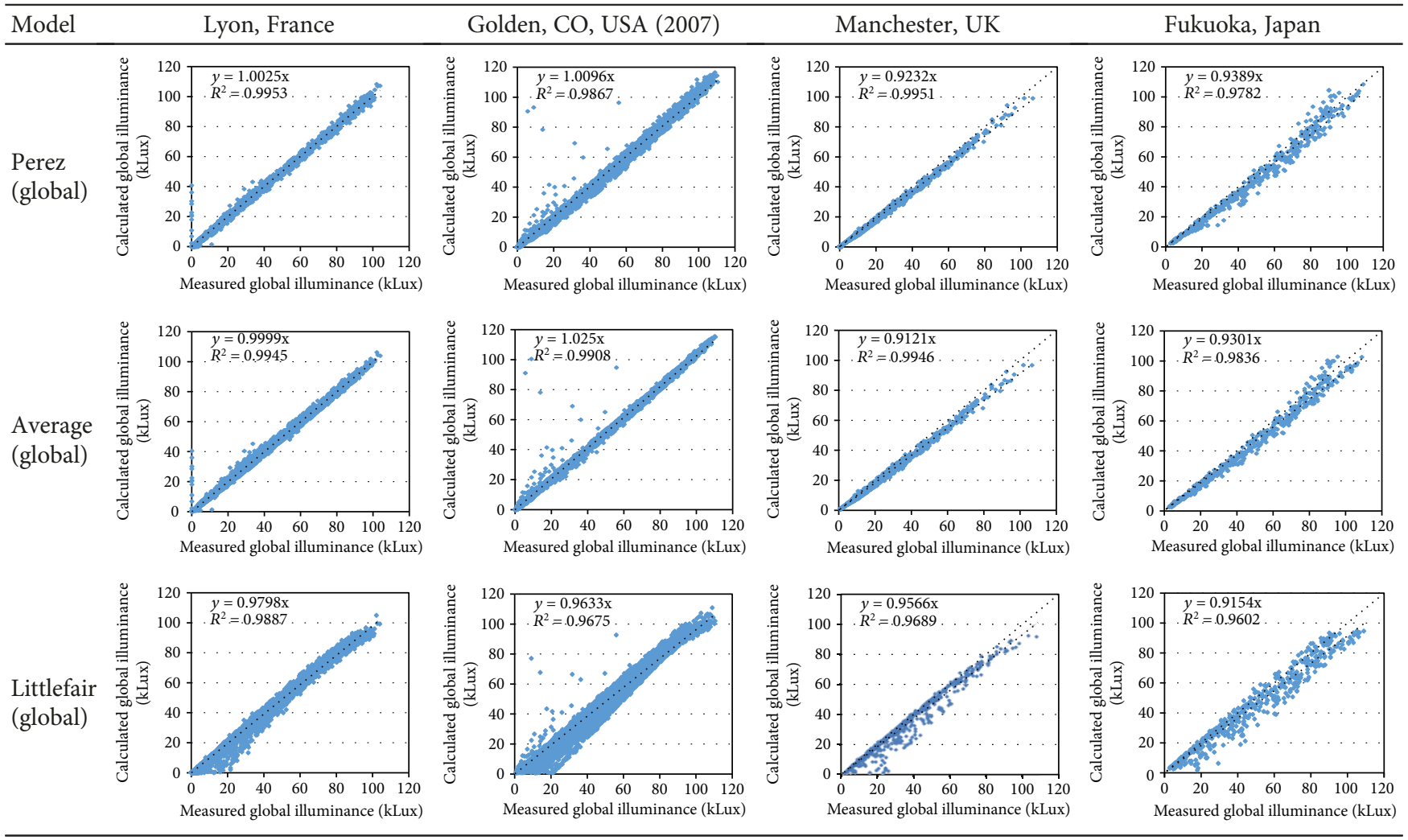

the errors are within tolerable range since the lowest $R^{2}$ is 0.96. Perez model has been usually recognized as the least local-dependent luminous efficacy model but this is partly true when global illuminance is concerned. In case of diffuse illuminance is concerned, as usual practices in building daylighting analysis, this model should be used with caution or with site-specific coefficients.

Tables 4 and 5 illustrate scatter plotting comparative analysis of global and diffuse luminous efficacy models performance for four worldwide cities. Regarding global illuminance data prediction, the Perez and average models show good agreement without bias through a little underestimation is shown in Manchester, UK, and Fukuoka, Japan. Littlefair model shows some systematic error by underestimating calculated illuminance when measured global illuminance is low. Regarding diffuse illuminance data prediction, the Perez model and average models show underestimation and this error increases in Manchester, UK, and Fukuoka, Japan. It is consistent with the literature review result in Table 1 that the Perez model shows tolerable 
TABLE 5: Comparative analysis of diffuse luminous efficacy models' performance for four worldwide cities.

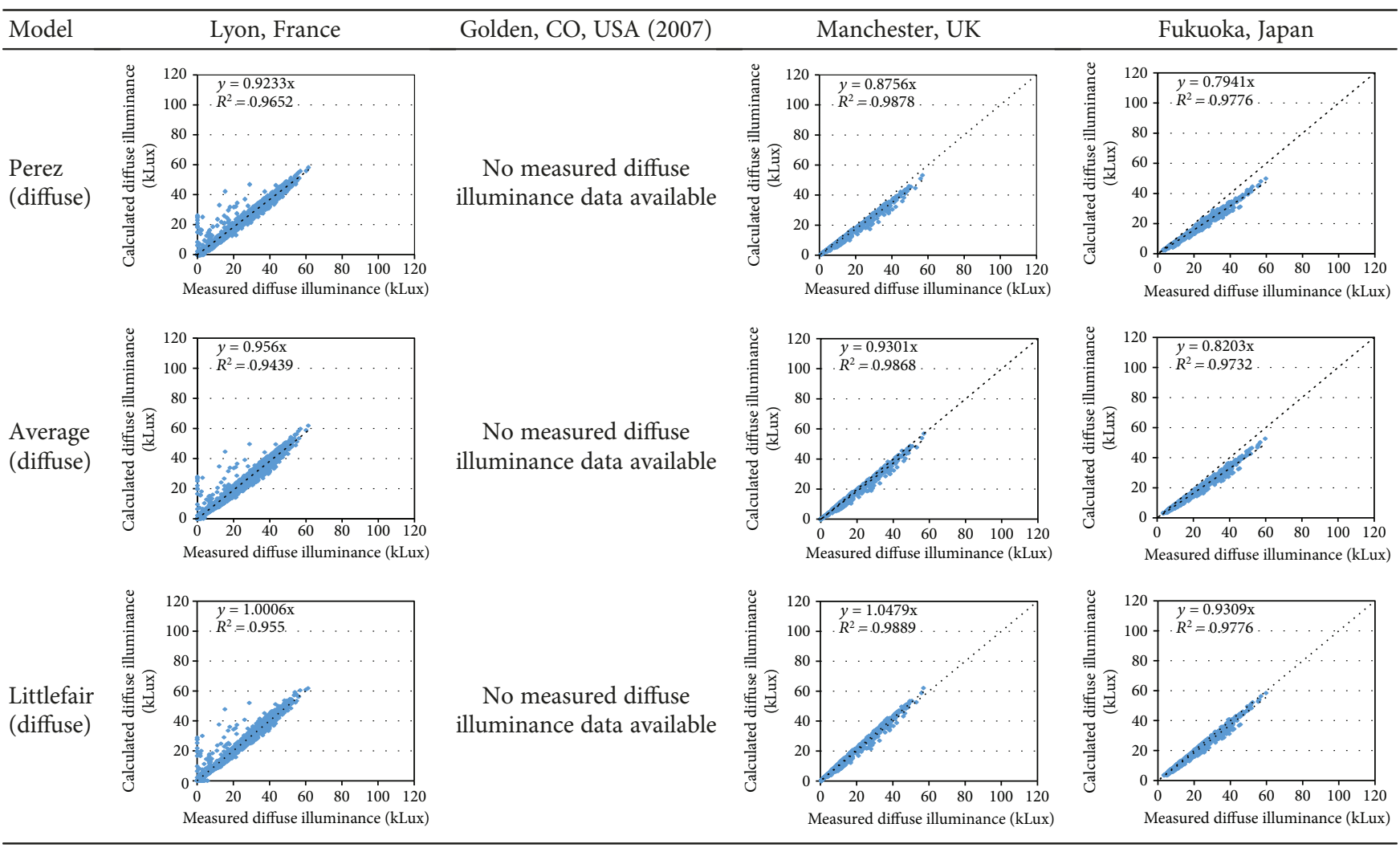

error in global illuminance prediction for the UK, Italy, and Japan. And, this error goes worse in diffuse illuminance prediction, by which goes up to $25 \%$ RMSE.

The comparative analysis conducted in this section confirms that the selected luminous efficacy models provide generally acceptable prediction accuracy of global illuminance if measured solar radiation data are available. However, as noted previously, measured solar radiation data are very rare and most building energy simulation tools use synthesized typical weather files. So, it is valuable to know the degree of the difference between measured solar data-based illuminance and modeled solar data-based illuminance.

The next section investigates the impact of solar radiation models on the accuracy of predicting global and diffuse illuminance.

\section{Impact of Estimated Solar Radiation Data from Solar Model on Luminous Efficacy Models}

In this section, calculated rather than measured solar radiation data are used as input variables for the luminous efficacy models. Recently, ASHRAE published IWEC2 weather files [23] for over 3000 worldwide cities. In the research, the modified Zhang and Huang Model [3] and Watanabe decomposition model [24] are selected for generating global and diffuse solar radiation because those models are verified as universally applicable solar models throughout their series of researches. The research [23] also selected the Perez model [1] to generate illuminance data. Therefore, this calculated solar data-based illuminance estimation analysis could be an indicator of how much the IWEC2 solar and illuminance data have dispersion and bias with respect to the measured solar radiation-based illuminance data. The data for Lyon, France (1994), and Manchester, UK (1993), are used in the analysis as good and worse agreement case cities, respectively, in terms of luminous efficacy model.

Figures 1(a) and 2(a) show scatter diagrams for predicted solar radiation using the modified Zhang and Huang model against measured data for global and diffuse solar radiation, respectively, for Lyon, France. Figures 1(b) and 2(b) compare measured illuminance data with predicted global and diffuse illuminance from Perez model with the calculated solar radiation model.

The prediction errors expressed in MBE (\%) and RMSE (\%) values for global and diffuse illuminance predictions using the Perez model are almost equal to those of global and diffuse solar radiation. This result indicates that most errors for predicting illuminance levels are attributed to errors in predicting solar radiation, and luminous efficacy model's error is unnoticeable. Similar errors (no bias but dispersion is wider) are found in comparative analysis for Manchester, UK, with 864 hourly data (covering 4 days per month) in Figures 3 and 4 . And the underestimation problem of the Perez model in Manchester, UK, is also consistent as measured solar radiation data analysis in Tables 4 and 5 . 


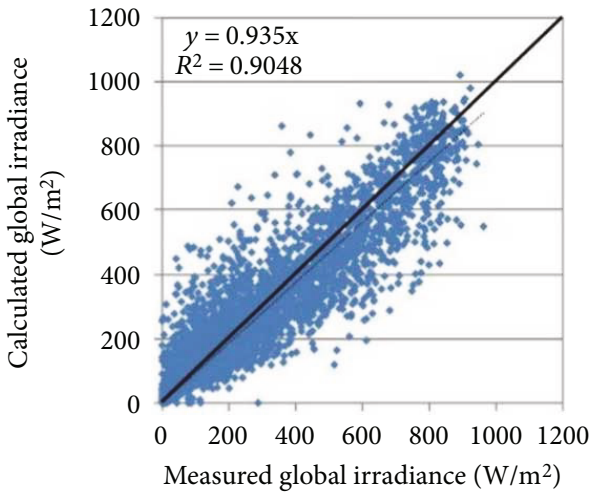

(a) Solar irradiance-Z\&H model (MBE: 0.3\%, RMSE: 27.3\%)

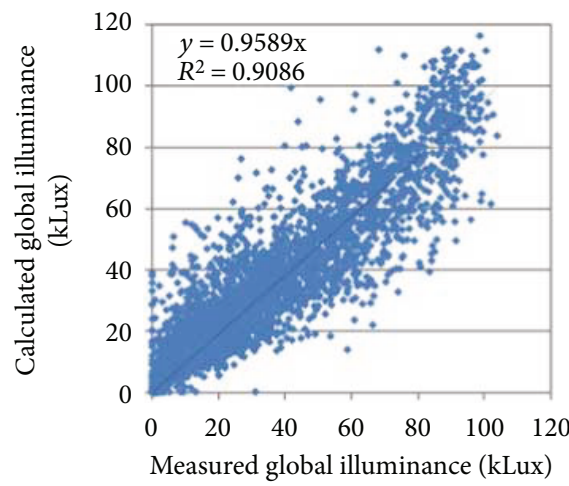

(b) Illuminance-Perez model

(MBE: $1.2 \%$, RMSE: 26.6\%)

Figure 1: Scatter plotting of global solar radiation and luminous efficacy models performance for Lyon, France (1994).

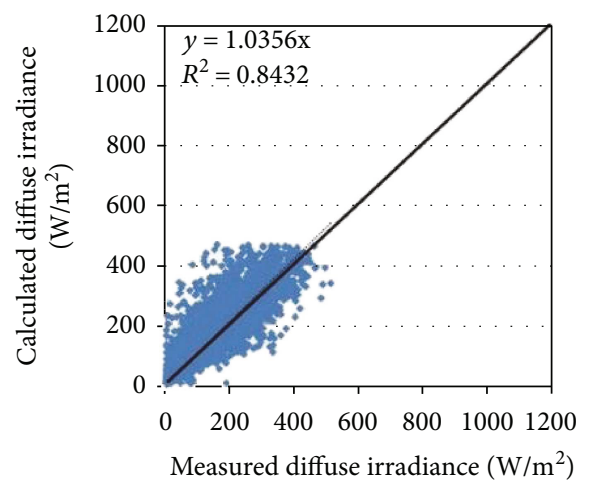

(a) Solar irradiance-Z\&H model (MBE: 6.4\%, RMSE: $33.8 \%$ )

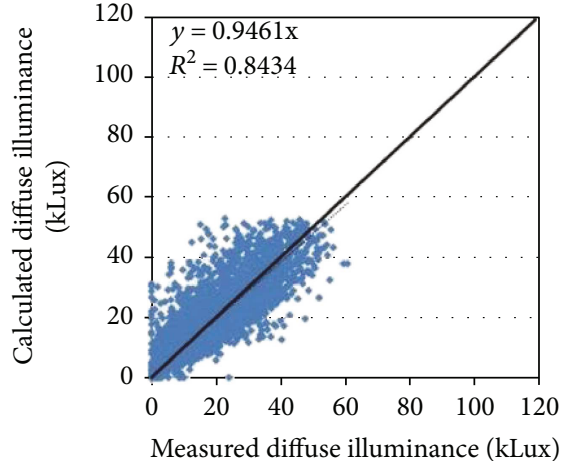

(b) Illuminance-Perez model

(MBE: 0.3\%, RMSE: 31.4\%)

FIGURE 2: Scatter plotting of diffuse solar radiation and luminous efficacy models performance for Lyon, France (1994).

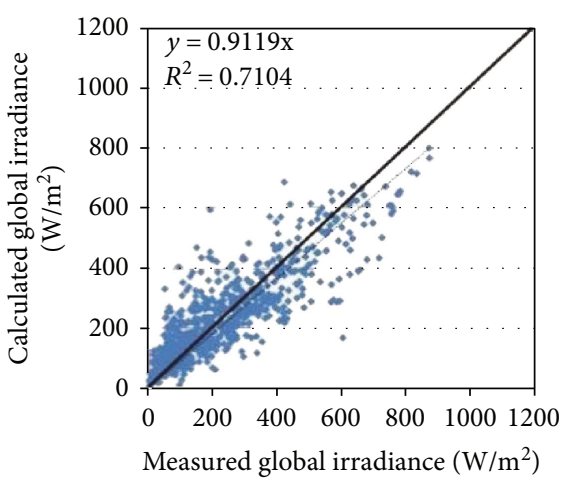

(a) Solar irradiance-Z\&H model (MBE: $3.0 \%$, RMSE: $41.3 \%)$

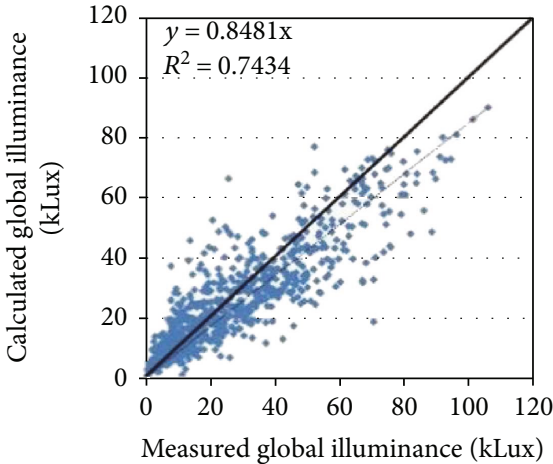

(b) Illuminance-Perez model (MBE: $-6.6 \%$, RMSE: $39.5 \%$ )

FIGURE 3: Scatter plotting of global solar radiation and luminous efficacy models performance for Manchester, UK (1993).

\section{Summary and Discussion}

Since after the universal solar radiation model is suggested, it is also necessary to decide a universal luminous efficacy model for building energy simulations and researches. Throughout various research reviews on this topic, some candidate models are selected as the universal luminous efficacy model. The performance of selected luminous efficacy models is evaluated against measured global and diffuse illuminance data from the four worldwide sites. It was consistently found that all the evaluated models provide good prediction performances for both global and diffuse 


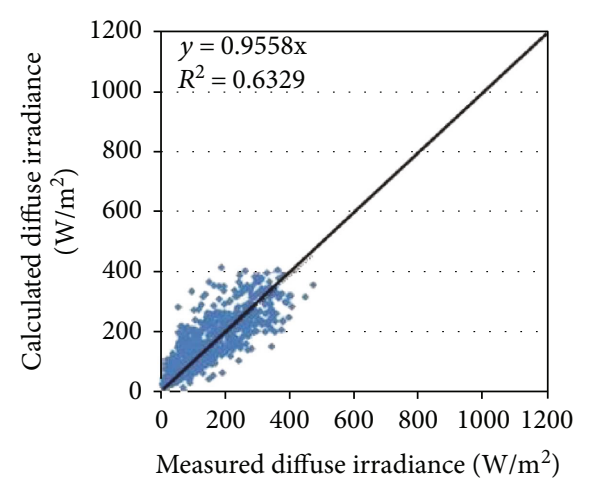

(a) Solar irradiance-Z\&H model

(MBE: 5.0\%, RMSE: 41.4\%)

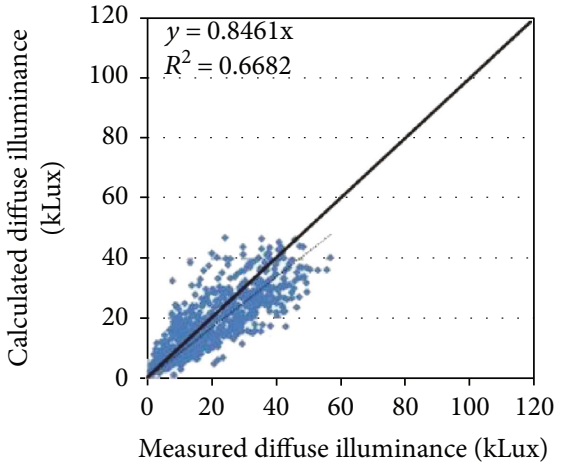

(b) Illuminance-Perez model

(MBE: -9.0\%, RMSE: 39.2\%)

FIgURE 4: Scatter plotting of diffuse solar radiation and luminous efficacy models performance for Manchester, UK (1993).

illuminance levels if measured global and diffuse solar radiation data are used as input variables. But, some underestimation problems in the cities of UK, Italy, and Japan are consistently found especially in the Perez diffuse luminous efficacy model.

However, this local coefficient-dependent problem is relatively trivial when luminous efficacy models are combined with solar radiation models, which is more common in building energy simulation. Since the error of the solar radiation model is transferred directly to the luminous efficacy model and this error is relatively larger than that of luminous efficacy model, the impact on the performance of luminous efficacy model is not heavier than using accurate solar radiation data. Because the average model needs sitefitted value for each site and the Littlefair model shows some biased prediction, the consecutive processing of the modified Zhang and Huang model and Perez luminous efficacy model could provide the best option to predict both global and diffuse solar radiation and illuminance with the current limited technology and measured data resource. But users of the model-based illuminance data should interpret their simulation results with the error (30\% 40\% in RMSE and $\pm 6 \%$ in $\mathrm{MBE})$ in predicting global and diffuse illuminance.

\section{Conclusion and Future Work}

Due to the lack of credible measured illuminance data of worldwide cities, it is not feasible to develop a universal luminous efficacy model, which is necessary for daylightrelated analysis. This paper suggested using the Perez luminous efficacy model as the universal model since it has relatively less locality originated bias and under- or overestimation problems. Regardless of such a problem of the luminous efficacy model, this paper estimated global and diffuse illuminance prediction errors when utilizing estimated solar radiation data, which is more common practice in fields.

It would be very worthwhile to expand this comparative analysis with more measured solar and illuminance data for the worldwide cities to have more confidence on the performance variations of the luminous efficacy models.

\section{Data Availability}

The data used to support the findings of this study are available from the corresponding author upon request.

\section{Conflicts of Interest}

The author declares that there is no conflict of interest regarding the publication of this paper.

\section{Acknowledgments}

The author would like to acknowledge the support (KIMPA2015-4070) from the Weather See-at Technology Development Program of Korea Meteorological Institute.

\section{References}

[1] R. Perez, P. Ineichen, R. Seals, J. Michalsky, and R. Stewart, "Modeling daylight availability and irradiance components from direct and global irradiance," Solar Energy, vol. 44, no. 5, pp. 271-289, 1990.

[2] Lawrence Berkeley National Laboratory, "DOE-2 Engineers Manual,” Report LA-8520-M., Report LBL-11353, LBNL, CA. US, 1982.

[3] D. Seo and M. Krarti, "Hourly solar radiation model suitable for worldwide typical weather file generation," Journal of Solar Energy Engineering, vol. 133, no. 4, article 041002, p. 8, 2011.

[4] S. Aydinli and J. Krochmann, "Data on daylight and solar radiation: guide on daylight," Draft for CIE TC, vol. 4, no. 2, 1983.

[5] W. Chroscicki, "Calculation methods of determining the value of daylight's intensity on the ground of photometric and actinometrical measurements," in Proceedings of CIE Conference, vol. 71, p. 24, Barcelona, Spain, 1971.

[6] P. J. Littlefair, "Measurements of the luminous efficacy of daylight," Lighting Research \& Technology, vol. 20, no. 4, pp. 177-188, 1988.

[7] T. Muneer and D. Kinghorn, "Luminous efficacy modelsevaluation against UK data," Journal of the Illuminating Engineering Society, vol. 27, no. 1, pp. 163-170, 1998.

[8] J. A. Olseth and A. Skartveit, "Observed and modelled hourly luminous efficacies under arbitrary cloudiness," Solar Energy, vol. 42, no. 3, pp. 221-233, 1989. 
[9] E. Ruiz, A. Soler, and L. Robledo, “Assessment of Muneer's luminous efficacy models in Madrid and a proposal for new models based on his approach," Journal of Solar Energy Engineering, vol. 123, no. 3, pp. 220-224, 2001.

[10] A. Pons, A. Barrio, and J. Campos, "Variation of the luminous efficacy of direct, global and diffuse solar radiation with atmospheric parameters," Lighting Research \& Technology, vol. 36, no. 1, pp. 31-41, 2004.

[11] N. Igawa, S. Shimasaki, and H. Nakamura, "A study on estimation of illuminance by irradiance," Journal of Architecture, Planning, Environment Engineering, AIJ, vol. 526, pp. 17-24, 1999, (in Japanese).

[12] N. Umemiya, K. Iinuma, T. Nishioka, and R. Okura, "Estimation of horizontal illuminance by measured sky luminance distribution," in Ninth International IBPSA Conference, pp. 1269-1275, Montréal, QC, Canada, 2005.

[13] T. Muneer and R. C. Angus, "Daylight illuminance models for the United Kingdom," Lighting Research \& Technology, vol. 25, no. 3, pp. 113-123, 1993.

[14] T. Muneer and R. C. Angus, "Luminous efficacy: evaluation of models for the United Kingdom," Lighting Research \& Technology, vol. 27, no. 2, pp. 71-77, 1995.

[15] D. Dumortier, "Modeling global and diffuse horizontal irradiances under cloudless skies with different turbidities," Report for JOULE 2 Project, CEC, Brussels, Belgium, 1994.

[16] M. J. Blackwell, "Five-year continuous recordings of total and diffuse solar irradiance at Kew Observatory," in Meteorological Resource Publication 895, Meteorological Office, London, UK, 1954.

[17] M. Cucumo, A. De Rosa, V. Ferraro, D. Kaliakatsos, and V. Marinelli, "Correlations of global and diffuse solar luminous efficacy for all sky conditions and comparisons with experimental data of five localities," Renewable Energy, vol. 33, no. 9, pp. 2036-2047, 2008.

[18] T. Muneer, C. Gueymard, and H. Kambezidis, Solar Radiation and Daylight Models, Elsevier, Butterworth-Heinemann, Oxford, UK, 2nd edition, 2004.

[19] E. Vartiainen, "A comparison of luminous efficacy models with illuminance and irradiance measurements," Renewable Energy, vol. 20, no. 3, pp. 265-277, 2000.

[20] IDMP, August 2008, http://idmp.entpe.fr/mesfr.htm.

[21] T. Muneer, N. Abodahab, G. Weir, and J. Kubie, Windows in Buildings: Thermal, Acustic, Visual and Solar Performance, Architectural Press, Oxford, UK, 2000.

[22] NREL, February 2010, http://www.nrel.gov/midc/srrl_bms/.

[23] Y. J. Huang, F. Su, D. Seo, and M. Krarti, "Development of 3012 IWEC2 weather files for international locations (RP1477)," ASHRAE Transactions, vol. 120, Part 1, pp. 340-355, 2014.

[24] T. Watanabe, Y. Urano, and T. Hayashi, "Procedures for separating direct and diffuse insolation on a horizontal surface and prediction of insolation on tilted surfaces," Transactions of the Architectural Institute of Japan, vol. 330, pp. 96-108, 1983. 

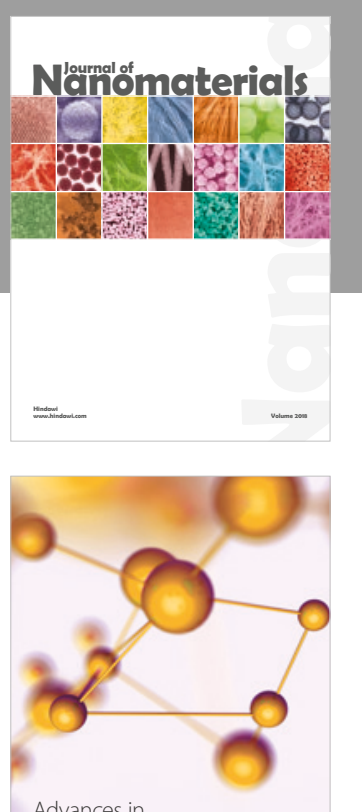

Physical Chemistry
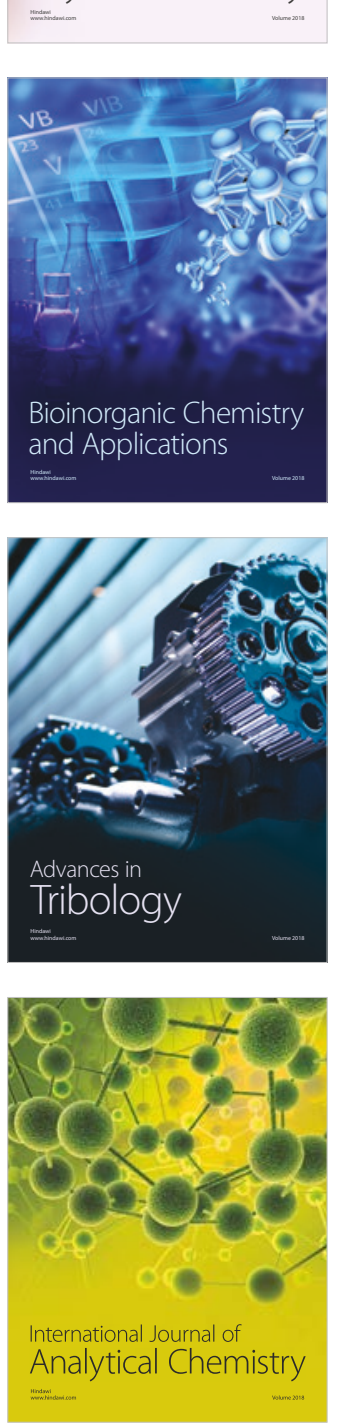

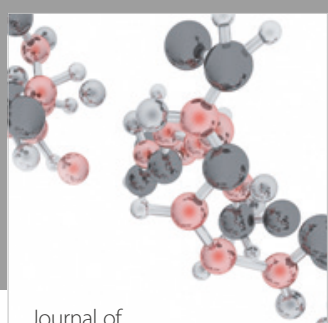

Analytical Methods

in Chemistry

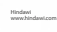

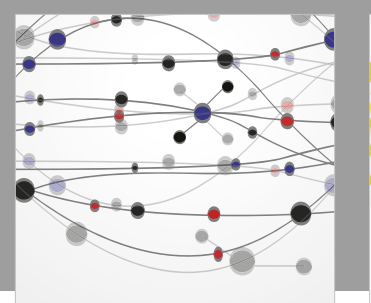

The Scientific World Journal

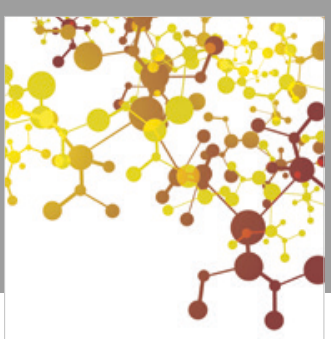

Journal of

Applied Chemistry
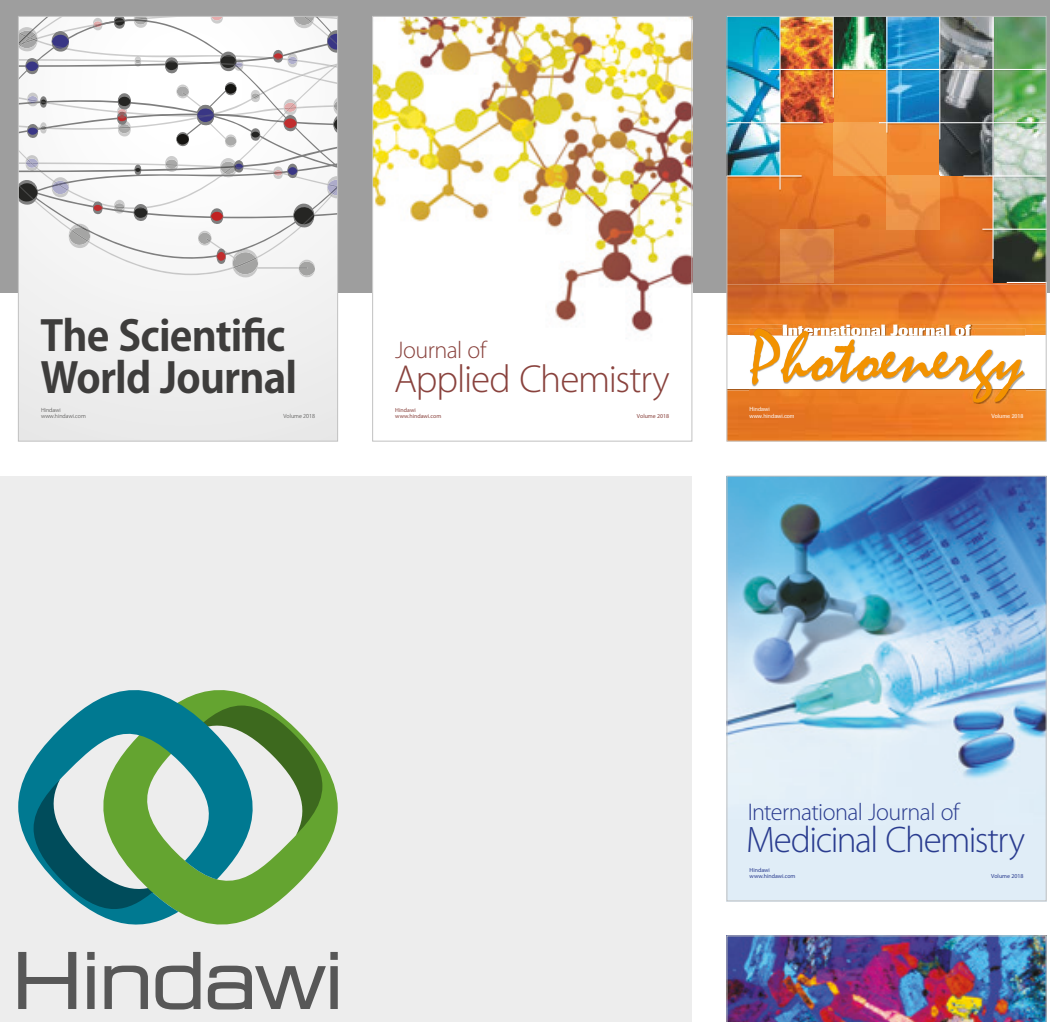

Submit your manuscripts at

www.hindawi.com
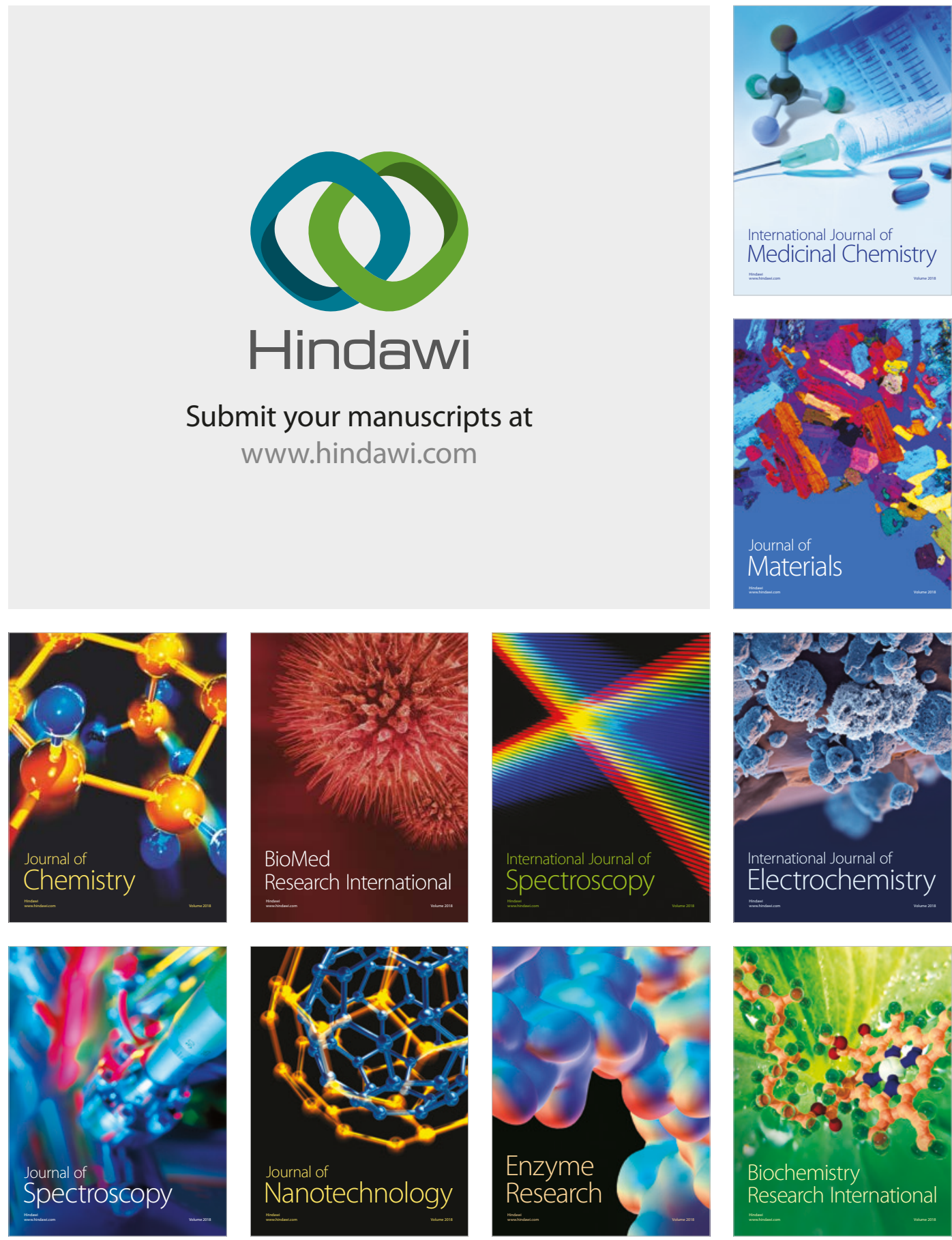
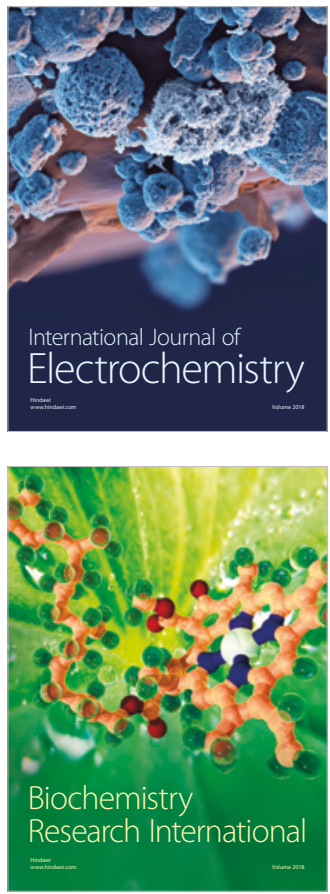